\title{
The Neurochemically Diverse Intermedius Nucleus of the Medulla as a Source of Excitatory and Inhibitory Synaptic Input to the Nucleus Tractus Solitarii
}

\author{
Ian J. Edwards, ${ }^{1 \star}$ Mark L. Dallas, ${ }^{1 \star}$ Sarah L. Poole, ${ }^{1}$ Carol J. Milligan, ${ }^{1}$ Yuchio Yanagawa, ${ }^{2}$ Gábor Szabó, ${ }^{3}$ \\ Ferenc Erdélyi, ${ }^{3}$ Susan A. Deuchars, ${ }^{1}$ and Jim Deuchars ${ }^{1}$ \\ ${ }^{1}$ Institute of Membrane and Systems Biology, University of Leeds, Leeds LS2 9JT, United Kingdom, ${ }^{2}$ Department of Genetic and Behavioral Neuroscience, \\ Gunma University Graduate School of Medicine, and Solution Oriented Research for Science and Technology, Japan Science and Technology Agency, \\ Maebashi 371-8511, Japan, and 3 Department of Gene Technology and Developmental Neurobiology, Institute of Experimental Medicine, H-1450 Budapest, \\ Hungary
}

Sensory afferent signals from neck muscles have been postulated to influence central cardiorespiratory control as components of postural reflexes, but neuronal pathways for this action have not been identified. The intermedius nucleus of the medulla (InM) is a target of neck muscle spindle afferents and is ideally located to influence such reflexes but is poorly investigated. To aid identification of the nucleus, we initially produced three-dimensional reconstructions of the InM in both mouse and rat. Neurochemical analysis including transgenic reporter mice expressing green fluorescent protein in GABA-synthesizing neurons, immunohistochemistry, and in situ hybridization revealed that the InM is neurochemically diverse, containing GABAegric and glutamatergic neurons with some degree of colocalization with parvalbumin, neuronal nitric oxide synthase, and calretinin. Projections from the InM to the nucleus tractus solitarius (NTS) were studied electrophysiologically in rat brainstem slices. Electrical stimulation of the NTS resulted in antidromically activated action potentials within InM neurons. In addition, electrical stimulation of the InM resulted in EPSPs that were mediated by excitatory amino acids and IPSPs mediated solely by $\mathrm{GABA}_{\mathrm{A}}$ receptors or by $\mathrm{GABA}_{\mathrm{A}}$ and glycine receptors. Chemical stimulation of the InM resulted in (1) a depolarization of NTS neurons that were blocked by NBQX (2,3-dioxo-6-nitro-1,2,3,4-tetrahydrobenzo[f]quinoxaline-7sulfonoamide) or kynurenic acid and (2) a hyperpolarization of NTS neurons that were blocked by bicuculline. Thus, the InM contains neurochemically diverse neurons and sends both excitatory and inhibitory projections to the NTS. These data provide a novel pathway that may underlie possible reflex changes in autonomic variables after neck muscle spindle afferent activation.

Key words: posture; neck; cardiovascular; respiration; medulla oblongata; autonomic

\section{Introduction}

Reflex changes in cardiorespiratory variables during body movements rely on interactions between the somatic and autonomic nervous systems. A prime example of such interaction is the somatosympathetic reflex, in which stimulation of thinly myelinated group III (A $\delta$ ) and unmyelinated group IV (C-fiber) limb muscle afferent fibers can reflexly increase cardiorespiratory output (Potts et al., 2000, 2003; Wilson, 2000). These reflexes are mediated via sensory afferent input to the spinal cord, which is then relayed to the nucleus tractus solitarius (NTS), a brainstem

Received Feb. 13, 2007; revised May 25, 2007; accepted June 20, 2007.

This work was supported in part by the Wellcome Trust (C.J.M. and J.D.) and Grants-in-Aid for Scientific Research from the Ministry of Education, Culture, Sports, Science and Technology and the Ministry of Health, Labor, and Welfare, Japan (Y.Y.). I.J.E. was supported by the Biotechnology and Biological Sciences Research Council. We acknowledge the contribution of Gareth Dobson, who was an undergraduate project student, to this work.

*I.J.E. and M.L.D. contributed equally and significantly to this work.

Correspondence should be addressed to either Jim Deuchars or Susan A. Deuchars, Institute of Membrane and Systems Biology, Garstang Building, University of Leeds, Leeds LS2 9JT, UK. E-mail: J.Deuchars@leeds.ac.uk or S.A.Deuchars@leeds.ac.uk.

DOI:10.1523/JNEUROSCI.0638-07.2007

Copyright $\odot 2007$ Society for Neuroscience $\quad$ 0270-6474/07/278324-10\$15.00/0 site for cardiorespiratory integration (Potts et al., 2003). Cardiorespiratory changes can also be evoked by stimulation of neck muscle afferents (Bolton et al., 1998; Bolton and Ray, 2000), proposed to contribute to alterations in cardiorespiratory outflow in preparation for a change in posture (Bolton and Ray, 2000). In contrast to limb afferents, the sensory signals from these muscles appear to be mediated by group IA muscle spindle afferents (Bolton et al., 1998). However, the neural pathways that link these afferent signals to cardiorespiratory control are completely unknown.

One target for sensory information from neck muscles is the cervical spinal cord where terminations can be found in the dorsal horn (although sparse) and the central cervical nucleus (CCN) (Bakker et al., 1984; Pfaller and Arvidsson, 1988; Prihoda et al., 1991). The CCN projection is generally considered to underlie spinal somatic reflex circuits, such as those for the tonic neck reflex involved in postural control (Wilson et al., 1984; Brink et al., 1985; Hongo et al., 1988; Popova et al., 1995). There is also a strong direct neck muscle afferent projection to the medulla oblongata where fibers terminate in the external cuneate nucleus and a nucleus located at the lateral edges of the dorsal aspect of the hypoglossal motor nucleus (XII), referred to either as the 
Table 1. Primary antibodies used for dual-labeling immunohistochemistry

\begin{tabular}{|c|c|c|c|c|}
\hline Genotype & $\begin{array}{l}\text { Primary } \\
\text { antibodies }\end{array}$ & Concentration & Species & Source \\
\hline \multirow[t]{3}{*}{ GAD65-GFP } & PV & $1: 5000$ & Goat & Swant (Bellinzona, Switzerland) \\
\hline & $C R$ & $1: 5000$ & Goat & Swant \\
\hline & $\mathrm{nNOS}$ & $1: 25,000$ & Sheep & Dr. P. Emson (The Babraham Institute, Cambridge, UK) \\
\hline \multirow[t]{3}{*}{ GAD67-GFP } & PV & $1: 5000$ & Goat & Swant \\
\hline & CR & $1: 5000$ & Goat & Swant \\
\hline & nNOS & $1: 25,000$ & Sheep & Dr.P. Emson \\
\hline \multirow[t]{9}{*}{ Wild type } & PV & 1:1000 & Mouse & Sigma \\
\hline & vs & & & \\
\hline & nNOS & $1: 25,000$ & Sheep & Dr.P. Emson \\
\hline & PV & $1: 1000$ & Mouse & Sigma \\
\hline & vs & & & \\
\hline & $C R$ & $1: 5000$ & Goat & Swant \\
\hline & $C R$ & $1: 5000$ & Goat & Swant \\
\hline & vs & & & \\
\hline & nNOS & $1: 1500$ & Mouse & Santa Cruz Biotechnology (Santa Cruz, CA) \\
\hline
\end{tabular}

power serial images were imported into Reconstruct (Fiala, 2005), and images were calibrated using a scale bar. The sections were then rigidly aligned using cytoarchitechtonic landmarks present on adjacent sections. The area occupied by neurons in the InM was then outlined on each section, and these outlines were used to generate a three-dimensional (3D) model of the nucleus; the InM was defined as the region of small neurons confined by the dorsal vagal nucleus (DVN), the XII, and fibers in the internal arcuate fiber bundle. The volume of the 3D model was then recorded. To calculate the length of the nucleus, the Z-trace tool was used to draw a straight line from the center of the cell population on the most caudal section where the InM could be identified through to the center of the cell population on the most rostral section. For reference, the central canal, XII, and DVN were also traced. The $3 \mathrm{D}$ reconstructions were then exported as DXF files and imported into Blender for smoothing and coloring.

\section{Calculating the number of neurons in the} InM using the optical dissector

intermediate nucleus of the medulla (InM), as first named by Ramón y Cajal (1995), or as a rostral continuation of the CCN (Bakker et al., 1984; Edney and Porter, 1986; Imamura et al., 1986; Stechison and Saintcyr, 1986; Pfaller and Arvidsson, 1988; Prihoda et al., 1991; Paxinos et al., 1999). However, regardless of terminology, this nucleus remains extremely poorly characterized in the brainstem.

Here, we test the hypothesis that neurons in the InM may be connected to regions in the brainstem associated with cardiorespiratory control, focusing on the NTS in this study. Because little information currently exists on the InM, we first define its cytoarchitecture in both rat and mouse. Using transgenic reporter mice, we estimate the proportion of InM neurons that are GABAergic and couple this to immunohistochemistry to examine neurochemical diversity. Monosynaptic excitatory and inhibitory projections from the InM to the NTS are shown. The results provide the first evidence for monosynaptic projections from the InM to the NTS through which proprioceptive neck sensory afferents may influence cardiorespiratory variables.

\section{Materials and Methods}

All experiments were performed under United Kingdom Home Office License and in accordance with the regulations of the United Kingdom Animals (Scientific Procedures) Act of 1986.

\section{Three-dimensional reconstructions of the InM from tissue stained with toluidine blue}

Three adult C57BL/6 mice (8-10 weeks) were anesthetized with intraperitoneal pentobarbitone sodium (Sagatal, $60 \mathrm{mg} / \mathrm{kg}$ ) and perfused transcardially with $200 \mathrm{ml}$ of ice-cold $4 \%$ paraformaldehyde (PFA) [in $0.1 \mathrm{~m}$ phosphate buffer (PB), $\mathrm{pH}$ 7.4]. The brains and spinal cords were removed and postfixed overnight in the same perfusate. After fixation, coronal sections of the medulla oblongata and cervical spinal cord were cut at $30 \mu \mathrm{m}$ and collected serially in PBS. Sections were then washed three times in PBS before being mounted on gelatinized microscope slides in serial order. Once dry, the slides were immersed in $0.1 \%$ toluidine blue in $50 \%$ isoprenalol for $2 \mathrm{~min}$. Slides were then dehydrated in a series of ethanols, cleared in two changes of xylene, and mounted in dibutyl phthalate xylene.

Low-power serial photomicrographs of the area containing the InM were taken using a Nikon (Surrey, UK) E600 microscope equipped with AcQuis image capture software (Synoptics, Cambridge, UK). Low-
To calculate the number of neurons present within a structure, the optical dissector method was used (Bonthius et al., 2004). Briefly, one of the first six sections to contain the InM was randomly selected. From this section, and every subsequent sixth section for the duration of the nucleus, live images of focusing through the InM at $63 \times$ magnification using an oil-immersion lens were viewed onscreen using a Zeiss (Oberkochen, Germany) axioscope microscope using Delta Pix image capture software. A uniform series of counting frames was randomly superimposed over the screen; each individual frame was small enough to allow numerous frames to fall within the viewed area but larger than an individual unit to be counted. The number of neurons in each frame was recorded, with neurons falling over the top and right edges of a frame being included and those falling over the bottom and left edges of a frame being excluded. The number of neurons counted within each frame and the number of counting frames used were recorded. These values were then used to calculate the neuronal density (ND) using the following formula:

$\mathrm{ND}=\Sigma($ number of cells counted $) /($ number of boxes $\times$ area of box $\times$ height of box).

The ND was then multiplied by the volume of the structure estimated by the $3 \mathrm{D}$ reconstruction to give an estimate of the number of neurons present within the structure.

As a control for the counting procedure, the volume of the adjacent XII was estimated from the reference traces created while reconstructing the InM. The same counting procedure as above was used to estimate the neuron density, and therefore estimations of the number of neurons in the XII could be made and compared with previously published data.

\section{$3 D$ reconstructions of the GABAergic neurons in the InM using transgenic mouse tissue}

We used glutamic acid decarboxylase (GAD) 67-green fluorescent protein (GFP) ( $\Delta$ neo) mice in which GFP is selectively expressed under the control of the endogenous GAD67 gene promoter (Tamamaki et al., 2003). In this study, these transgenic mice were called GAD67-GFP mice for simplicity. These transgenic mice were backcrossed to C57BL/6 mice. The other transgenic mouse line used expressed GFP under control of the GAD65-GFP promoter, driving expression of GFP almost exclusively to GABAergic neurons in many brain regions. The generation and analysis of this GAD65-GFP mouse line has been described in detail previously (Lopez-Bendito et al., 2004). In both mouse lines, the GFP-expressing cells were located in regions corresponding to GAD cells reported by both in situ hybridization and immunohistochemistry (Fong et al., 2005) and were absent from neurons that do not express GAD (e.g., hypoglossal 
A
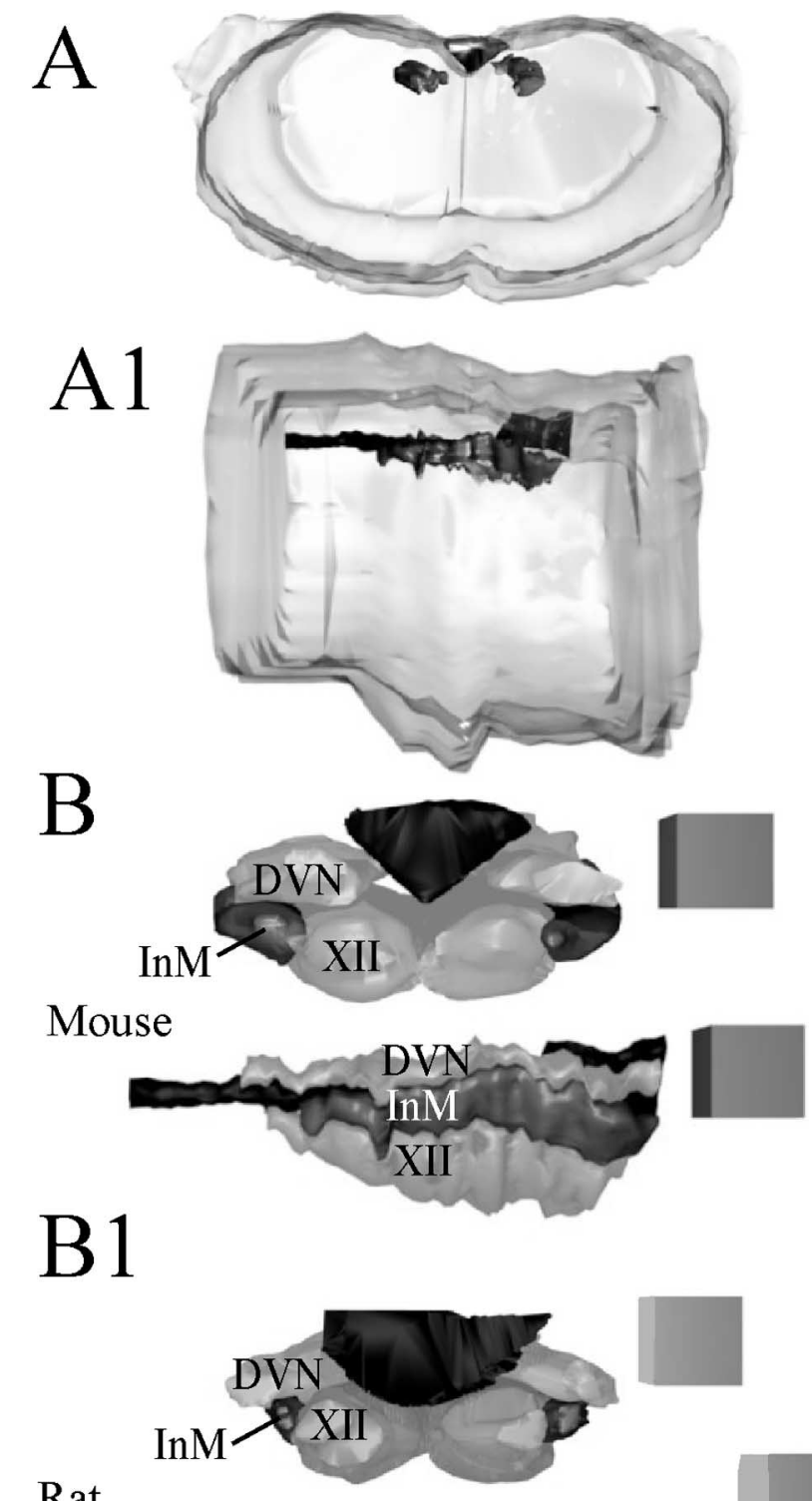

Rat
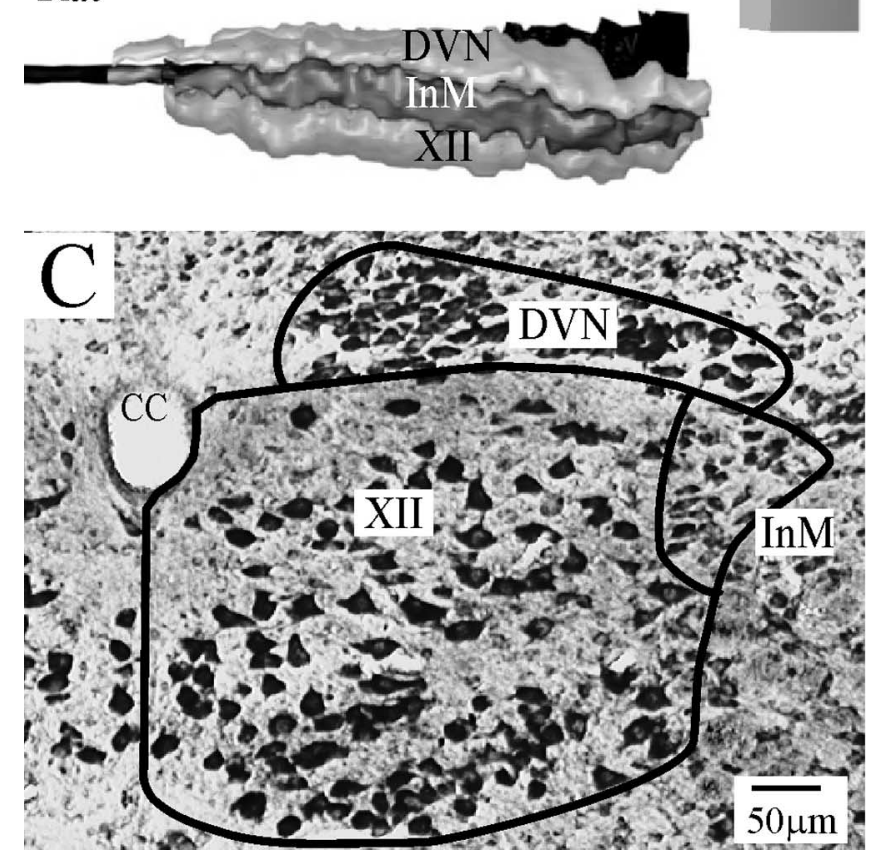

motor neurons). The extent and specificity of GFP expression in GAD cells in these mice is considered further in the Discussion.

Three C57BL/6 GAD65-GFP (Lopez-Bendito et al., 2004) and three C57BL/6 GAD67GFP( $\Delta$ neo) (Tamamaki et al., 2003) mice (adult; age, $8-10$ weeks) were perfused and sectioned as described above. Serial sections were incubated in mouse primary antibodies raised against GFP ( $1: 1000$ in PBS containing 0.1\% Triton X-100; Invitrogen, Paisley, UK) for $16 \mathrm{~h}$ at $4^{\circ} \mathrm{C}$. Sections were washed and incubated in a biotinylated anti-mouse secondary antibody (1:250 in PBS; Vector Laboratories, Peterborough, UK) for $4 \mathrm{~h}$ at room temperature before washing and incubation in ExtrAvidin peroxidase (1:1500 in PBS; Sigma, Poole, Dorset, UK) overnight at $4^{\circ} \mathrm{C}$. Peroxidase was then visualized with the VIP substrate kit ( 1 drop each of solutions 1, 2, and 3 in $10 \mathrm{ml}$ of $0.1 \mathrm{M} \mathrm{PB}$; Vector Laboratories). Sections were mounted onto gelatinized microscope slides and treated as described previously.

Characterization of GAD-GFP cells using immunohistochemistry for calcium-binding proteins and neuronal nitric oxide synthase Dual-labeling immunohistochemistry was performed on tissue from three C57BL/6 GAD65-GFP and three C57BL/6 GAD67-GFP mice. The mice were perfused with $4 \%$ PFA, and brainstem sections were obtained as above. Sections from each mouse genotype were incubated in primary antibodies against parvalbumin (PV), calretinin (CR), or neuronal nitric oxide synthase (nNOS) as shown in Table 1. Three C57BL/6 mice were also perfused, postfixed, and sectioned as above. Tissue from these wildtype mice was incubated in combinations of PV, CR, and nNOS primary antibodies as shown in Table 1. All primary antibody incubations were for 26-40 h. After the incubation, sections were washed three times for $10 \mathrm{~min}$ in PBS before incubation in secondary antibodies. For each antibody combination, sections were incubated in $\mathrm{Cy} 3$-conjugated anti-goat secondary antibodies (1:500 in PBS; Jackson ImmunoResearch, Luton, $\mathrm{UK})$ for $2 \mathrm{~h}$ at room temperature and washed three times in PBS. The transgenic mouse tissue was then air dried and mounted on glass microscope slides before coverslipping in Vectashield (Vector Laboratories). The wild-type tissue was further incubated in an Alexa488-conjugated anti-mouse secondary antibody (1:1000 in PBS; Invitrogen) for $2 \mathrm{~h}$ at room temperature. This tissue then had a final three washes in PBS and was mounted in the same way as the transgenic mouse tissue.

\section{Data presentation}

All numerical values are displayed as mean \pm SEM. Where it is necessary to state the number of animals and or the number of cells counted to obtain values, $n$ is the number of animals used and $N$ is the number of cells counted.

\section{In situ hybridization}

Rats $(n=5,200 \mathrm{~g})$ were anesthetized with sodium pentobarbitone (Sagatal, $60 \mathrm{mg} \mathrm{kg}^{-1}$, i.p.) and perfused transcardially with $4 \% \mathrm{PFA}$, and coronal $(30 \mu \mathrm{m})$ sections of the medulla were cut on a vibrating microtome (Leica, Milton Keynes, UK). In situ hybridization was conducted using previously published protocols (Stornetta et al., 2002). To visualize GABAergic neurons, single-stranded digoxigenin-UTP-labeled (Roche Molecular Biochemicals, Basel, Switzerland) sense (control) and antisense riboprobes were transcribed from a $2.3 \mathrm{~kb}$ GAD65 DNA template plasmid kindly supplied and previously characterized by A. Tobin (University of California, Los Angeles, CA) (Wuenschell et al., 1986; Esclapez

Figure 1. Serial reconstruction of the $\ln M . A, A 1$, Guide images showing an approximate outline of the surface of the mouse medulla oblongata and the position of the central canal/ fourth ventricle in relation to this, as viewed from either a more rostral location $(A)$ or a lateral view (A1). The DVN, XII, central canal, and InM are the darker areas at the dorsal aspects of the diagram. A zoom-in on this region is shown in the panels below for both mouse and rat. $\boldsymbol{B}, \boldsymbol{B 1}$, 3 D reconstructions from serial toluidine blue-stained mouse $(\boldsymbol{B})$ and rat $(\boldsymbol{B} 1)$ tissue viewed from a rostral position shows that the $\mathrm{InM}$ (dark gray) lies slightly lateral to the XII and ventral to the DVN. Looking from a lateral position, the reconstructions show that all three structures have a similar rostrocaudal extent. All edges of cubes in reconstructions are $300 \mu \mathrm{m}$. C, Representative micrograph of a toluidine blue section indicating the anatomical boundaries of the $\operatorname{lnM}$ used in the reconstruction. CC, Central canal. 

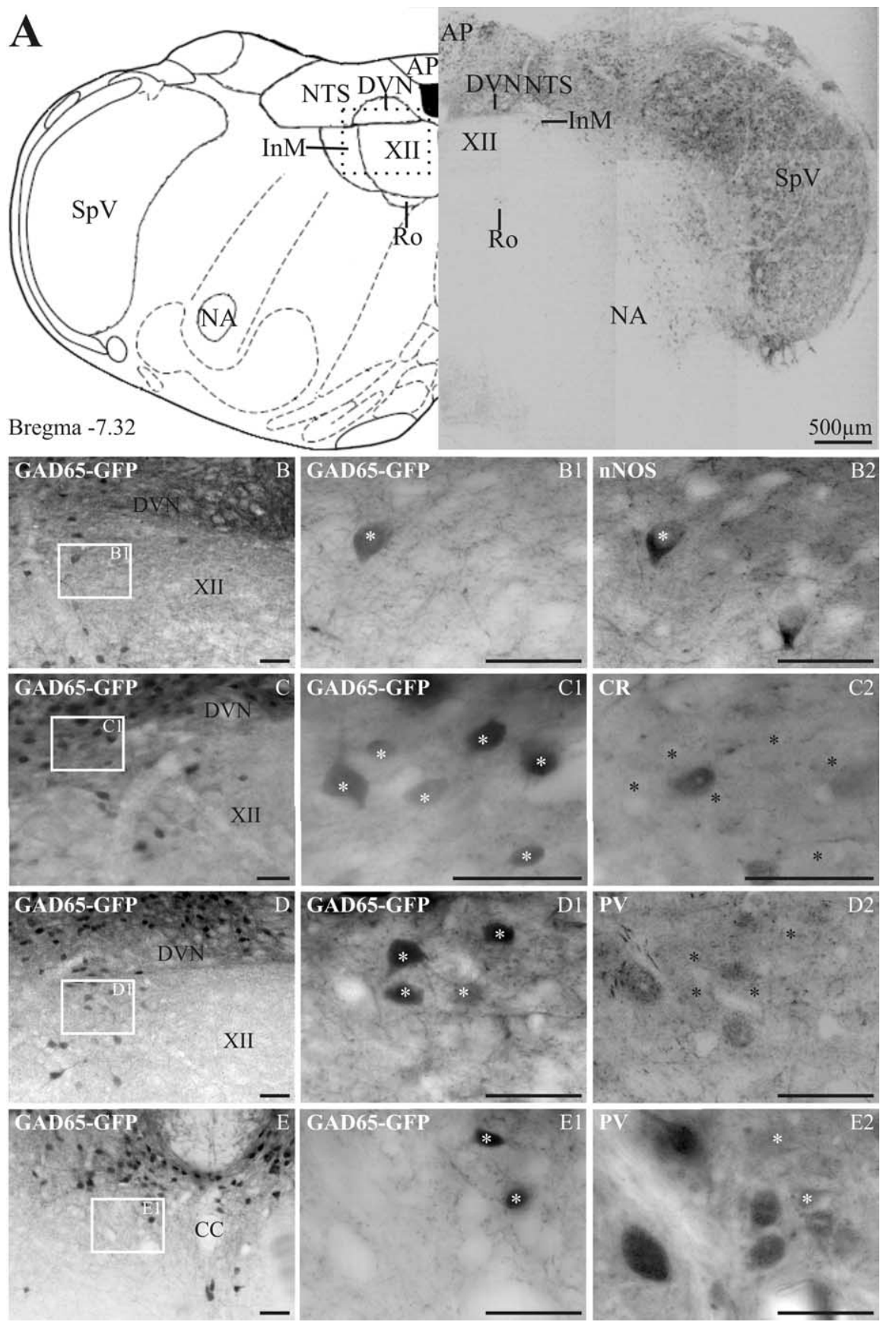

Figure 2. In GAD65-GFP tissue, GFP-expressing neurons are found in many dorsal medullary structures. In the InM, GFP is preferentially found in neurons expressing nNOS. $A$, The left panel is an orientation diagram showing the location of various nuclei at the level represented by the low-power montage of GFP-expressing neurons illustrated in the right panel. The boxed area represents the approximate region of the micrographs in $\boldsymbol{B}-\boldsymbol{D}$. AP, Area postrema; Ro, nucleus of Roller; SpV, spinal trigeminal; $N A$, nucleus accumbens. $\boldsymbol{B}-\boldsymbol{D}$, Low-power images showing the location of GFP-expressing neurons within the InM. The boxed area in each image is shown at a higher magnification in $\mathbf{B 1}-\mathbf{D 1}$, respectively. $\boldsymbol{B 2}$, nNOS immunoreactivity within the same region as $\boldsymbol{B}$, showing one GAD65-GFP-positive and one GAD65-GFP-negative neuron. C2, CR immunoreactivity on the same section of medulla; no neurons with CR immunoreactivity also express GFP. D2, PV immunoreactivity within the same region showing no colocalization between PV and GFP. E, A low-power image of the CCN showing the location of GFP-expressing neurons. E1, A more magnified image of the area indicated in $\boldsymbol{E}$. E2, PV-immunoreactive neurons within the $\mathrm{CCN}$ are GFP negative and are located ventral to GFP neurons. The asterisks in $\boldsymbol{B} \mathbf{2}-\mathbf{E 2}$ indicate the location of GFP-positive neurons visible in respective panels $\boldsymbol{B} 1-\mathbf{E 1}$. Scale bars: $\boldsymbol{B}-\mathbf{E 2}, 50 \mu \mathrm{m}$. CC, Central canal.

et al., 1993). For glutamatergic neurons, sense and antisense vesicular glutamate transporter 2 (VGluT2) riboprobes were transcribed from a $3.3 \mathrm{~kb}$ DNA template kindly supplied and previously characterized by R. Stornetta (University of Virginia, Charlottesville, VA) (Stornetta et al., 2002). Hybridized mRNA was visualized with nitroblue tetrazolium chloride and 5-bromo-4-chloro-3-indolyl phosphate diluted in Tris- $\mathrm{HCl} / \mathrm{MgCl}_{2}, \mathrm{pH} 9.5$.

\section{Image capture and manipulation}

Low- and high-power photomicrographs were taken with a Nikon E600 microscope equipped with epifluorescence, using AcQuis image capture software. Images were then imported into Corel Draw 12 where their brightness, contrast, intensity, and gamma were adjusted, if appropriate.

\section{Electrophysiology}

Adult rats aged $18-21 \mathrm{~d}$ were terminally anesthetized with sodium pentobarbitone (Sagatal, $120 \mathrm{mg} \mathrm{kg}^{-1}$, i.p.). The brain was dissected out and placed in ice-cold aerated $\left(95 \% \mathrm{O}_{2}, 5 \%\right.$ $\mathrm{CO}_{2}$ ) sucrose artificial CSF (aCSF) containing (in mM) 217 sucrose, $26 \mathrm{NaCHO}_{3}, 3 \mathrm{KCl}, 2$ $\mathrm{MgSO}_{4}, 2.5 \mathrm{NaH}_{2} \mathrm{PO}_{4}, 2 \mathrm{CaCl}_{2}$, and 10 glucose. Slices $(250-300 \mu \mathrm{m})$ of the medulla oblongata were obtained using a Vibroslice and transferred to a holding chamber. The holding chamber contained aerated $\left(95 \% \mathrm{O}_{2}, 5 \% \mathrm{CO}_{2}\right)$ aCSF (in mM): $124 \mathrm{NaCl}, 26 \mathrm{NaHCO}_{3}, 3 \mathrm{KCl}, 2$ $\mathrm{MgSO}_{4}, 2.5 \mathrm{NaH}_{2} \mathrm{PO}_{4}, 2 \mathrm{CaCl}_{2}$, and 10 glucose.

Visualized patch-clamp recordings were performed using an upright microscope (Olympus BX50WI; Optivision, Yorkshire, UK). All of these experiments were performed at room temperature. Patch electrodes were filled with an intracellular solution consisting of (in $\mathrm{mm}$ ) $130 \mathrm{~K}$-gluconate, $11 \mathrm{EGTA}, 2 \mathrm{MgCl}_{2}, 1 \mathrm{CaCl}_{2}$, 10 HEPES, $0.3 \mathrm{NaGTP}$, and $2 \mathrm{Na}_{2}$ ATP. Recordings were made in current-clamp mode, using an Axopatch ID (Molecular Devices, Foster City, CA), from neurons around the solitary tract and within the InM using standard procedures. Pipette resistance was measured at 4-6 $\mathrm{M} \Omega$ and compensated for using the Axopatch 1D. Data capture was performed using Clampex version 8 .

To investigate the presence of synaptic connections, a bipolar stimulating electrode connected to an isolated stimulator (model DS2A; Digitimer, Hertfordshire, UK) was placed in the InM and stimulated at twice the threshold for activation (duration, $100 \mu \mathrm{s}$ ) to evoke postsynaptic potentials within ipsilateral NTS neurons, or in the NTS, just medial to the solitary tract, to evoke antidromic action potentials within ipsilateral InM neurons. The distance between the stimulating electrode and the recording electrode was measured, which gave an average distance of $220 \mu \mathrm{m}$. To determine the nature of these synaptic potentials, kynurenic acid, bicuculline, 2,3-dioxo-6-nitro-1,2,3,4-tetrahydrobenzo[f]quinoxaline-7-sulfonoamide (NBQX), and strychnine (all from Sigma) were applied in the superfusate. All concentrations stated were the final drug concentration in the recording chamber.

For the microinjection studies, a patch pipette was knocked back to a tip diameter of $10 \mu \mathrm{m}$, filled with $40 \mathrm{~mm}$ glutamate (Sigma), and positioned within the InM with glutamate applied by pressure injection through a pneumatic picopump (PV800; World Precision Instruments, Sarasota, FL) with a pulse duration of 5-15 $\mathrm{ms}$ and a pulse pressure of 5-20 psi.

Off-line data analysis was performed using Clampfit 8.1 software (Mo- 
lecular Devices) with a sampling frequency of 5 $\mathrm{kHz}$ after low-pass filtering at $1 \mathrm{kHz}$. The effects of drugs were determined using the paired Student's $t$ test on the preapplication and postapplication of drugs. Differences were considered significant when $p<0.05$. All values stated are as the mean \pm SEM.

\section{Results}

Nucleus length, volume, and neuron numbers estimated from

\section{$3 \mathrm{D}$ reconstructions}

Toluidine blue staining of sections from entire medulla oblongata revealed neurons at mid-rostrocaudal levels of the InM as medium-sized spindle-shaped neurons in mice and rats $(21 \times 12$ and $19 \times 11 \mu \mathrm{m}$, respectively). The size, shape, and location of these neurons were used as guides for tracing the rostrocaudal extent of the nucleus (Fig. 1). At approximately $-8.2 \mathrm{~mm}$ caudal to bregma in mice and $-15.0 \mathrm{~mm}$ caudal to bregma in rats, these mediumsized spindle-shaped neurons could not be followed further, although larger, PVcontaining cells were located more ventrally in a region similar to the CCN (Figs. $2 E, 3 E)$. Thus, the InM appears to be distinguishable from the CCN on the basis of neuronal size, shape, and location.

Using cell size, shape, and position as criteria for being an InM neuron, serial reconstruction of the InM was conducted in both rats and mice, and measurements were taken (Table 2). As a control for the counting procedure, the number of neurons within the adjacent XII was also calculated, and this was found to be similar to previously reported figures: $1825 \pm 138$ $(n=3)$ compared with 1639 (Haenggeli and Kato, 2002).

\section{GFP expression in GAD65-GFP} transgenic mice can be observed in neurons containing $\mathrm{nNOS}$ or PV but not those containing $\mathrm{CR}$

Immunohistochemistry to reveal GABAergic neurons in the brainstem reveals only a small proportion of the estimated GABAergic population, likely because of low levels of GAD or GABA in cell bodies. Therefore, to investigate the GABAergic neurons in the InM, we used two strains of transgenic mice in which GAD-expressing neurons are labeled by GFP expressed under control of GAD65 (Lopez-Bendito et al., 2004) or GAD67 (Tamamaki et al., 2003) promoters.

In GAD65-GFP transgenic mouse tissue, GFP-expressing neurons were concentrated in the dorsal portion of the medulla oblongata, with very light terminal labeling observed in the ventrally located olivary complex (Fig. 2A). Strong GFP expression was observed in the spinal trigeminal nucleus and NTS with smaller populations
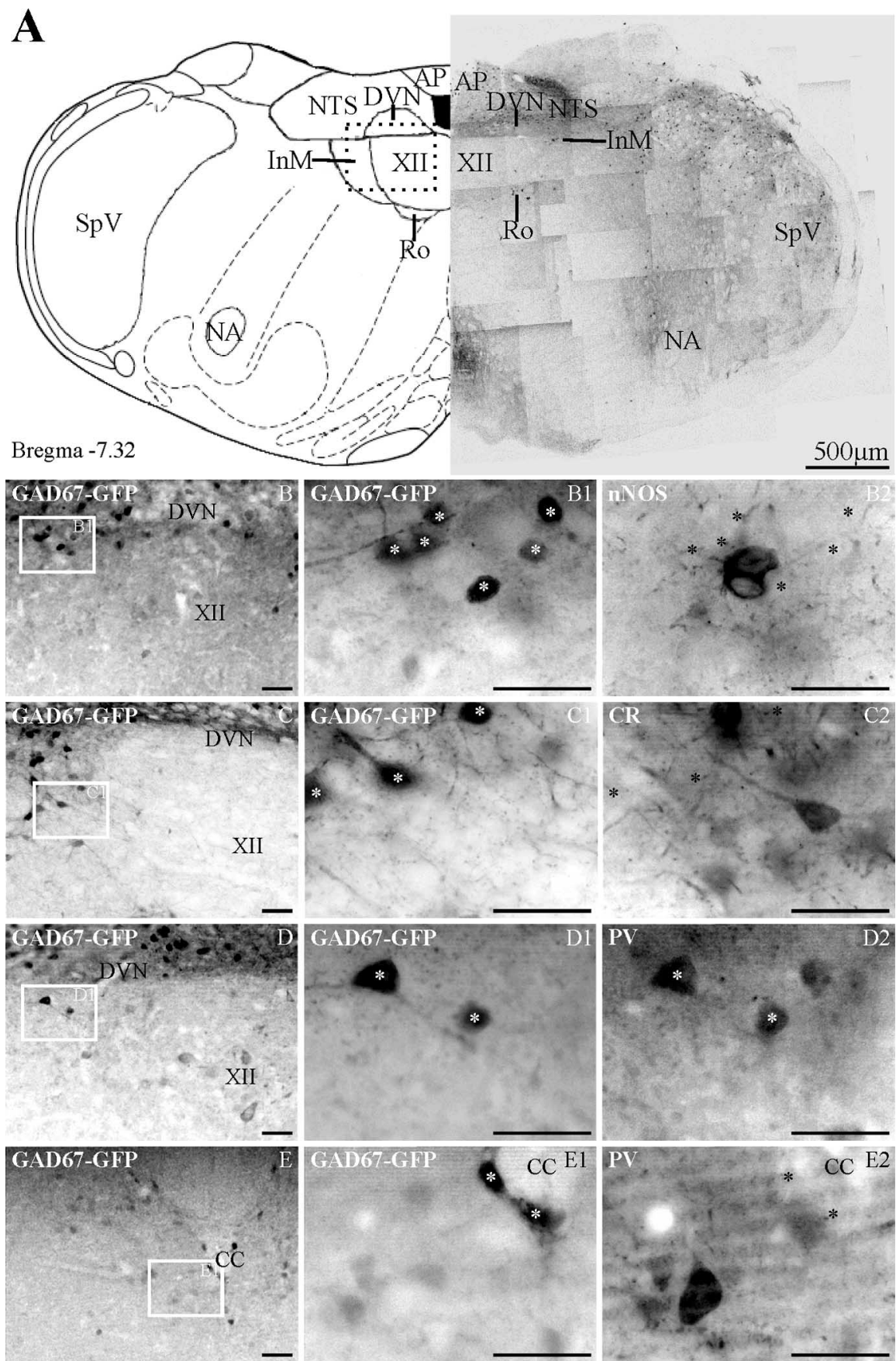

Figure 3. In GAD67-GFP tissue, GFP-expressing neurons are found in many dorsal medullary structures and the inferior olives. In the InM, GFP is preferentially found in neurons expressing PV. $A$, The left panel is an orientation schematic illustrating the location of various nuclei at the level represented by the low-power montage of GFP-expressing neurons shown in the right panel. The box in the dorsal medulla represents the approximate area of the micrographs in $\boldsymbol{B}-\boldsymbol{D}$. AP, Area postrema; Ro, nucleus of Roller; SpV, spinal trigeminal; NA, nucleus ambiguus. $\boldsymbol{B}-\boldsymbol{D}$, Low-power images showing the location of GFP-expressing neurons within the InM. The boxed area in each image is shown at higher magnification in $\boldsymbol{B 1}-\mathbf{D 1}$, respectively. $\boldsymbol{B 2}$, nNOS immunoreactivity within the same region as $\boldsymbol{B}$ 1, showing no colocalization with GAD67-GFP cells. $\mathbf{C}$, The same area as $\mathbf{C}$ illuminated to reveal only CR immunoreactivity, illustrating CR neurons that do not colocalize with GAD67-GFP neurons. D2, PV immunoreactivity within the same region as $\mathbf{D 1}$, indicating colocalization of PV and GAD67-GFP neurons. $\boldsymbol{E}$, A low-power image of the CCN showing the location of GFP-expressing neurons. $\boldsymbol{E 1}$, A more magnified image of the area indicated in $\boldsymbol{E}$. E2, PV-immunoreactive neurons within the $C C N$ are GFP negative and are located ventral to GFP neurons. The asterisks in B2-E2 indicate the location of GFP-positive neurons visible in respective panels B1-E1. Scale bars: $\boldsymbol{B}-\mathbf{E 2}, 50 \mu \mathrm{m}$. CC, Central canal.

seen in the InM and nucleus of Roller. Within the InM, GFPexpressing neurons were found along the dorsal extreme of the nucleus, mainly concentrated at the lateral edge. Serial reconstructions of the InM on GAD65-GFP transgenic mouse tissue 
Table 2. Comparison between mice and rats of the neuronal architecture of the $\ln \mathrm{M}$

\begin{tabular}{lll}
\hline & Mouse & Rat \\
\hline Cell diameter $(\mu \mathrm{m})$ & $21.2 \pm 1.2 \times 12.0 \pm 1.0$ & $19.5 \pm 0.7 \times 11.1 \pm 0.4$ \\
Rostral pole $(\mathrm{mm}$ to bregma) & -7.2 & -12.8 \\
Caudal pole $(\mathrm{mm}$ to bregma) & -8.2 & -15.0 \\
Total length $(\mathrm{mm})$ & $1.01 \pm 0.07$ & $2.2 \pm 0.21$ \\
Cross-sectional area (mid level, & & \\
$\left.\quad \mathrm{mm}^{2}\right)$ & $0.025 \pm 0.003$ & $0.020 \pm 0.003$ \\
Volume $\left(\mathrm{mm}^{3}\right)$ & $0.025 \pm 0.005$ & $0.033 \pm 0.005$ \\
Number of cells & $1288 \pm 92(n=3)$ & $2543 \pm 150(n=3)$ \\
\hline
\end{tabular}

revealed that there were $92 \pm 16$ GFP-expressing neurons $(n=$ 3 ), which accounts for $\sim 7 \%$ of the total neuron population. Of the antigens investigated, nNOS and PV were found in a similar region of the InM to the GFP-expressing neurons, whereas the pool of CR-immunoreactive neurons was located more ventrally. A subpopulation of the GFP neurons contains nNOS $(27.6 \pm$ $8.4 \% ; N=17$ of $62 ; n=3$ ); typically, nitrergic neurons that do not colocalize with GFP are located in a more ventral position to the GFP-positive neurons. Another subpopulation contains PV $(3.3 \pm 1.7 \% ; N=3$ of $60 ; n=3)$, with PV-immunoreactive neurons that do not express GFP being located more medially than the double-labeled GFP-positive cells. Finally, none of the GFP-expressing neurons contain CR $(N=0$ of $66 ; n=3)$.

\section{GFP expression in GAD67-GFP transgenic mice can be observed in neurons containing PV and, to a lesser extent, CR and $\mathrm{nNOS}$}

In tissue from GAD67-GFP transgenic mice, GFP is expressed in all of the areas described for GAD65-GFP mouse medulla, as well as strong expression of terminals being evident in the inferior olivary complex (Fig. 3A). Within the InM, the GFP-containing neurons have a similar distribution to that described for GAD65GFP in that the cells are located along the dorsal extreme of the nucleus; however, there is a greater degree of extension into the ventral portion of the InM. In GAD67-GFP transgenic mouse tissue, the InM contains $340 \pm 26$ GFP-expressing neurons $(n=$ 3 ), accounting for $26 \%$ of the total number of neurons in the InM. Of the GFP-containing neurons, a subpopulation contains PV $(40.3 \pm 16.7 \% ; N=79$ of $217 ; n=3)$ and smaller subpopulations contain CR $(20.4 \pm 3.6 \% ; N=41$ of $200 ; n=3)$ or $n N O S$ $(12.9 \pm 3 \% ; N=7$ of $69 ; n=3)$.

\section{Colocalization of nNOS, PV, and CR within the InM}

Dual labeling for nNOS and CR shows that both antigens are never observed in the same neurons $(n=3)$. Immunohistochemistry for nNOS and PV on the same tissue sections shows that the two antigens do not colocalize within the $\operatorname{InM}(n=3)$. CR and PV can also exist in the same cells because $\sim 40 \%$ of PV also express CR, whereas $13 \%$ of CR have PV (PV with CR, $N=17$ of $58=40.5 \pm$ $13 \%$; CR with PV, $N=17$ of $124=12.9 \pm 0.8 \% ; n=3$ ).

\section{Monosynaptic projections from the InM to the NTS}

We next sought to identify some outputs of the InM. Because neurons in the InM were labeled retrogradely by large injections of tracer into the NTS (Esteves et al., 2000), we tested whether there was a connection between these two nuclei. The relatively small diameter of the InM makes it difficult to accurately restrict tracer injections, so we used electrophysiological techniques with visualized guidance to place stimulating electrodes in the InM and recording electrodes in the NTS, or vice versa as appropriate. Rat brainstem was used to provide a larger degree of spatial separation between recording and stimulating electrodes than was possible in the mouse. The electrophysiological studies were optimally performed in young rats although the anatomical studies were performed in adult tissue, because preliminary studies in young rats and mice did not reveal any differences in neurochemistry to the adult tissue (data not shown), and the younger ages provide more viable slices for electrophysiological recordings.

Whole-cell patch-clamp recordings from InM neurons in brainstem slices revealed that they fired action potentials in response to electrical stimulation in the medial NTS $(N=12$ of 12$)$. These responses were attributable to antidromic activation of the InM neurons as follows: (1) the response was all or none in response to stimuli of different intensities (Fig. 4A); (2) the evoked action potentials occurred with an extremely constant latency (Fig. $4 \mathrm{~B}$ ); and (3) hyperpolarization of the InM neurons resulted in loss of response and revealed the initial segment spike but no underlying synaptic potentials (Fig. 4C). Close proximity of the stimulating and recording electrodes and fast pathway conduction precluded the collision test. The latency of conduction for this pathway was $1.2 \pm 0.09 \mathrm{~ms}$, and assuming a direct axon pathway $(\sim 220 \mu \mathrm{m})$, the estimated conduction velocity was 0.18 $\mathrm{m} / \mathrm{s}$, which suggests activation of $\mathrm{c}$ fibers. It must also be noted that these experiments were performed at room temperature, which slows conduction velocity considerably, and also that measurement of such short-distance pathways is difficult and may lead to errors in this estimation. Synaptic potentials were not detected in InM neurons after stimulation in the medial NTS $(N=13)$.

\section{GABAergic neurons in the InM project to the NTS}

To test whether GABAergic neurons in the InM projected to the NTS, we recorded from medial NTS neurons and stimulated the InM electrically in the presence of the excitatory amino acid (EAA) blocker kynurenic acid (1 mM). The NTS neurons were depolarized to $0 \mathrm{mV}$ to inactivate the voltage-gated sodium channels and hence prevent action potential generation, as well as to increase the driving force for chloride ion movement and enhance the amplitude of IPSPs. InM stimulation evoked IPSPs in all NTS neurons tested $(N=13$ of 13$)$, with a latency of $8 \pm 0.6$ $\mathrm{ms}$, an amplitude of $5.8 \pm 0.4 \mathrm{mV}$, a $10-90 \%$ rise rate of $0.5 \pm$ $0.05 \mathrm{mV} \mathrm{ms}^{-1}$, and a width at half-amplitude of $49.6 \pm 1.8 \mathrm{~ms}$ (Fig. 5). The latency of these inhibitory synaptic responses was considerably higher than the latency of antidromic-evoked responses, likely attributable to a long synaptic delay as a result of recordings being conducted at room temperature (Sabatini and Regehr, 1996), but is consistent with an 8-18 ms latency reported for the slightly longer monosynaptic connection from the NTS to the nucleus ambiguus (Neff et al., 1998). These IPSPs were mediated solely by $\mathrm{GABA}_{\mathrm{A}}$ receptors in 10 of 13 NTS neurons because they were completely abolished by $10 \mu \mathrm{M}$ bicuculline (Fig. $5 B, C)$. In 3 of 13 NTS neurons, IPSPs were only partially blocked by a similar concentration of bicuculline (Fig. $5 C$ ): the remaining component was glycine receptor mediated because it was abolished by $2 \mu \mathrm{M}$ strychnine (Fig. $5 C$ ). This inhibitory response was likely attributable to direct activation of a monosynaptic pathway because the responses exhibited constant latency and were present in EAA antagonists (Fig. 5). The sweep-to-sweep variation in onset latencies for 10 IPSPs was also measured, and the average value of this variation was $55.8 \pm 5.7 \mu \mathrm{s}$ (Fig. 5B1), which also indicates a monosynaptic pathway (Doyle and Andresen, 2001). In addition, microinjection of glutamate into the InM in 
the presence of EAA blockers [kynurenic acid $(1 \mathrm{mM})$ or NBQX $(20 \mu \mathrm{M})$ ] evoked hyperpolarizations in NTS neurons $(N=$ 4 of 4) (Fig. 5), indicating that the local glutamate microinjection activated GABAergic neurons in the InM that projected to the NTS.

We next verified that the InM of the rat does indeed contain GABAergic neurons using in situ hybridization to localize the mRNA for the GABA-synthesizing enzymes GAD65 or GAD67. This demonstrated that GAD67 and GAD65 are expressed by neurons in the InM ( $n=5$ rats) (Fig. 5). The methods required for in situ hybridization did not permit additional studies of the other antigens in these sections.

\section{Glutamatergic neurons in the InM project to the NTS}

The electrophysiological experiments above also revealed excitatory projections from the InM to the NTS. Examination of these evoked EPSPs in 10 of 13 NTS neurons revealed a latency of $5.2 \pm 0.2 \mathrm{~ms}$, an amplitude $6.1 \pm 0.45 \mathrm{mV}$, a $10-90 \%$ rise rate of $0.72 \pm 0.07 \mathrm{mV} / \mathrm{ms}$, and a width at half-amplitude of $52.4 \pm 3.96 \mathrm{~ms}$ (Fig. 6).

These EPSPs were blocked by application of kynurenic acid (1 $\mathrm{mm}$ ), indicating that they were mediated by EAA receptors (Fig. $6)$. Once more, the monosynaptic nature of this pathway was further verified using sweep-to-sweep variation in onset latencies for 10 EPSPs, and the average value of this variation was $51.8 \pm$ $4.4 \mu \mathrm{s}$ (Fig. 6 B1). Selective activation of cell bodies in the InM by microinjection of glutamate-evoked depolarizations in NTS neurons were also blocked by the non-NMDA antagonist NBQX (20 $\mu \mathrm{M} ; N=5$ ) (Fig. 6). This blockade was not attributable to prevention of activation of InM neurons because recordings from InM neurons indicated that glutamate microinjections into the InM overcame the blockade of non-NMDA receptors by $20 \mu \mathrm{M}$ NBQX to locally excite the neurons $(N=2)$ (Fig. 6).

In situ hybridization confirmed that neurons in the InM expressed mRNA encoding the vesicular glutamate transporter VGluT2 (Fig. 6) ( $n=6$ rats), indicating that these neurons are glutamatergic and excitatory in function (Takamori et al., 2000; Fremeau et al., 2001, 2004). Thus, the presence of glutamatergic neurons in the InM as revealed by the presence of VGluT2 mRNA is consistent with monosynaptic EPSPs evoked in NTS neurons by stimulation in the InM.

\section{Discussion}

We have uncovered monosynaptic projections to neurons in the NTS from a little described nucleus, the InM. We also characterized the InM in both mouse and rat in terms of its cytoarchitecture and neurochemistry, revealing a neurochemically rich nucleus containing both GABAergic and glutamatergic neurons. Both sets of neurons innervate NTS neurons as revealed by electrophysiological studies. This first investigation of the connection between the InM and the NTS therefore sets the stage for subsequent investigations into the function and anatomy of the InM.

\section{Potential functional roles of the InM and its projection to the NTS}

The InM has previously been shown to receive afferent inputs from neck muscles (Bakker et al., 1984; Edney and Porter, 1986; Imamura et al., 1986; Stechison and Saintcyr, 1986; Pfaller and Arvidsson, 1988; Prihoda et al., 1991; Paxinos et al., 1999). Neck muscle afferent stimulation is involved in postural reflexes such as the cervicocollic reflex and interacts with information from the vestibular system to maintain posture. However, the separation of the afferent inputs to the InM from those to the CCN and vestibular nuclei suggest that the InM inputs and neurons participate in discrete circuits, possibly with a distinct functional role.

Activation of neck muscle spindle afferents via neck flexion can initiate an increase in heart rate, muscle sympathetic nerve activity, and arterial blood pressure (Kuwagata et al., 1991; Shortt and Ray, 1997). This reflex sympatho-excitation has been attributed to the activation of the otolith organs in the vestibular system (Yates and Miller, 1994); however, it is likely that there is another component to the reflex because it is still evident where the vestibular system is inactive, such as in brain-dead patients (Kuwagata et al., 1991). This component has been suggested to arise from the dorsal neck musculature, with stimulation of nerves arising from these muscles causing a reflex increase in splanchnic, hypoglossal, and abdominal nerve activity (Bolton et al., 1998). Furthermore, the stimulus intensities used were consistent with those that would activate muscle spindle and Golgi tendon organ afferents. Because this cervico-sympathetic reflex appears to originate from muscle spindles in the dorsal neck musculature, it is very likely that the suboccipital muscle group is involved in the reflex because these muscles have an extremely high muscle spindle content (Richmond and Abrahams, 1975; Kulkarni et al., 2001). Additional evidence for the involvement of the suboccipital muscle group in the cervico-sympathetic reflex comes from changes in blood pressure associated with chiroprac- 

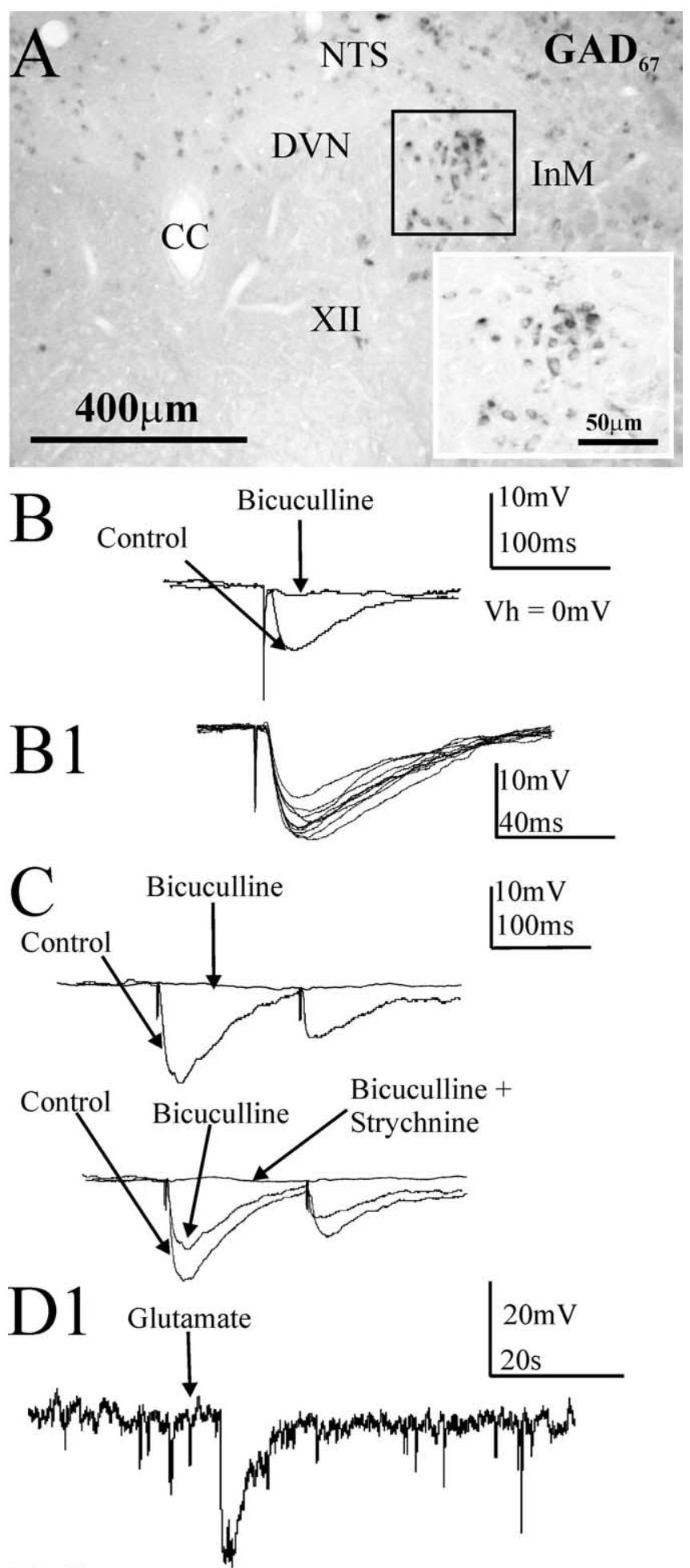

D2 Glutamate

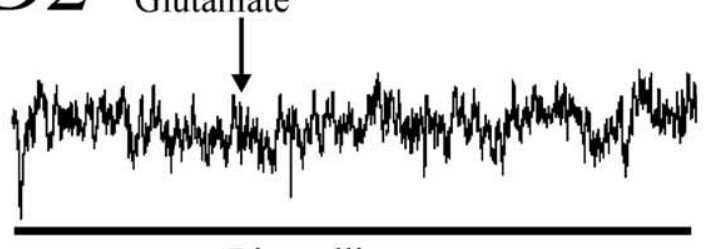

Bicuculline

Figure 5. A monosynaptic inhibitory projection from the InM to the NTS in the rat is reflected by GAD67 expression in InM neurons. $A$, In situ hybridization studies localized neurons within the InM positive for a GAD67 mRNA probe. The inset is a higher magnification of the boxed area. tic manipulations of the $\mathrm{C} 1$ vertebrae (McKnight and DeBoer, 1988; Knutson, 2001), which would result in altering the length of fibers in the suboccipital muscle group. The projection from the InM to the NTS identified in this study therefore places it in an ideal position to mediate cardiorespiratory changes to neck muscle afferent stimulation, because the NTS is a major integratory area for autonomic control circuits (Potts, 2002). Future studies are therefore required to examine the role of these neck afferents in cardiorespiratory regulation.

\section{The InM contains neurochemically diverse neurons}

The results from this study and others reveal that the InM is neurochemically rich. Here, we have shown that the InM contains neurons expressing VGluT2, GAD65 and/or GAD67, PV, $\mathrm{CR}$, and/or nNOS with varying degrees of colocalization. In addition, InM neurons in previous studies have been found to express nNOS (Esteves et al., 2000). Furthermore, the InM has been identified as containing neurons expressing mRNA for the neuronal glycine transporter (GlyT2) (Tanaka et al., 2003) as well as a dense site of preproenkephalin mRNA-containing neurons (Morita et al., 1990). This current study provides some insight into the patterns of coexpression in the InM, but the rich diversity means that more studies are required to fully determine the neurochemistry of the neurons in the nucleus.

The differential patterns of colocalization of GFP in the two different transgenic mouse strains with nNOS (GAD65>GAD67) and PV (GAD67>GAD65) highlights intriguing differences underlying the GFP expression in these cells. Several factors may contribute to such differences. First, the different transgenic mouse strains we used to identify GADexpressing neurons appear to reliably label GABAergic neurons (Tamamaki et al., 2003; Lopez-Bendito et al., 2004; Marowsky et al., 2005; Zhang et al., 2006) but may not label all GAD neurons in every CNS region. Nevertheless, the GAD67-GFP mouse line was created using homologous recombination, and as such, all neurons that express GAD67 would be expected to drive the expression of GFP (Tamamaki et al., 2003), and this situation has been described in several CNS regions (Ono et al., 2005) including the brainstem [Li et al. (2005), their Fig. 2]. On the other hand, the GAD65-GFP mouse line was created using pronuclear injection, and the control of expression in this way means that it is possible that neurons that should express GFP do not, although no aberrant expression of GFP would be predicted (Lopez-Bendito et al., 2004). Indeed, GFP in GAD65-GFP mice appears to be rarely expressed in PV neurons (Lopez-Bendito et al., 2004), consistent

\footnotetext{
$\leftarrow$

$\boldsymbol{B}$, An example of an IPSP recorded in current clamp in an NTS neuron evoked by electrical stimulation of the $\mathrm{InM}$ in the presence of $1 \mathrm{~mm}$ kynurenic acid. The cell is held at $0 \mathrm{mV}$ to inactivate the sodium channels and prevent action potentials and to increase the driving force for the chloride ion movements, enhancing the IPSP amplitude. In this example, application of $10 \mu \mathrm{m}$ bicuculline blocked this response. B1, Example of 10 consecutive IPSPs recorded from a NTS cell in response to electrical stimulation in the InM, highlighting the minimal synaptic jitter in the inhibitory pathway between the InM and NTS and consistent with a monosynaptic connection. $C$, Example of differing pharmacology of the evoked IPSPs. In the top trace, the IPSP (control trace) was completely abolished by $10 \mu \mathrm{m}$ bicuculline, indicating that it was mediated solely by $G_{A B A_{A}}$ receptors. The bottom trace is an IPSP mediated by both $G_{A B A_{A}}$ and glycine receptors as revealed by coapplication of bicuculline and strychnine $(2 \mu \mathrm{m})$. $\boldsymbol{D}$, An example of a hyperpolarization within an NTS neuron in response to local microinjection of $40 \mathrm{~mm}$ glutamate in the InM at a holding potential of $0 \mathrm{mV}$. D1, Local application of glutamate competitively overcomes the bath-applied EAA receptor blocker kynurenic acid to activate NTS-projecting GABAergic neurons in the InM. D2, This response was blocked by bath application of $10 \mu \mathrm{M}$ bicuculline. CC, Central canal.
} 
with our finding in this current study in which colocalization of GFP with PV was more prominent in GAD67-GFP mice. Curiously, GFP colocalized more with nNOS in GAD65-GFP than GAD67-GFP tissue. However, it is possible that all GAD65 neurons also express GAD67 but that there are GAD67 cells that do not express GAD65, and so the percentage of colocalization of nNOS with GAD67 seems lower. Nevertheless, this is currently conjecture because although it has previously been suggested that GAD65 and GAD67 are coexpressed in brainstem neurons (Stornetta and Guyenet, 1999), the authors do indicate that they did not exhaustively search all brainstem GABAergic neurons.

Our electrophysiological studies also hint at distinct populations of GABAergic neurons in the InM that project to the NTS. Electrical or chemical stimulation of the InM revealed two populations of IPSPs: those completely blocked by bicuculline or others that required both bicuculline and the glycine receptor antagonist strychnine for complete blockade. Consistent with a monosynaptic glycinergic pathway, mRNA for the neuronal glycine transporter (GlyT2) has been illustrated in the region of the InM (Tanaka et al., 2003). However, whether GAD and GlyT2 mRNA is coexpressed is impossible to tell at this stage without dual expression studies either using the GAD-GFP mice and/or dual in situ hybridization. It is clearly possible that the mixed IPSPs are a result of activation of separate glycinergic and GABAergic InM neurons. Nevertheless, in the spinal cord, Mackie et al. (2003) described the presence of GlyT2 in terminals containing predominantly the GAD67 isoform but not in those predominantly containing the GAD65 isoform. It is therefore possible that the two populations of IPSPs elicited in NTS neurons by InM stimulation are attributable to activation of distinct GABAergic neurons, with one population also containing glycine.

Low percentages of neurons in the InM express GABAergic phenotypes (GAD65-GFP, 7\%; GAD67-GFP, 25\%), comparable with estimates of GABAergic neurons in other CNS regions [rat basal forebrain, $\sim 34 \%$ (Gritti et al., 2006); cat gracile nucleus, 28\%, and internal cuneate, 25\% (Heino and Westman, 1991)]. Although unable to quantify results of in situ hybridization, we were able to identify that the InM also contains neurons expressing VGluT2, a glutamate vesicle transporter that identifies glutamatergic neurons (Takamori et al., 2000). This is consistent with the electrophysiology, which revealed that electrical stimulation of NTS neurons evoked monosynaptic EPSPs mediated by EAA receptors. Because immunohistochemistry for VGluT2 detects protein only in terminals, future studies of coexpression patterns in the InM will need to rely on in situ hybridization, although many antigens do not survive the in situ processing, or
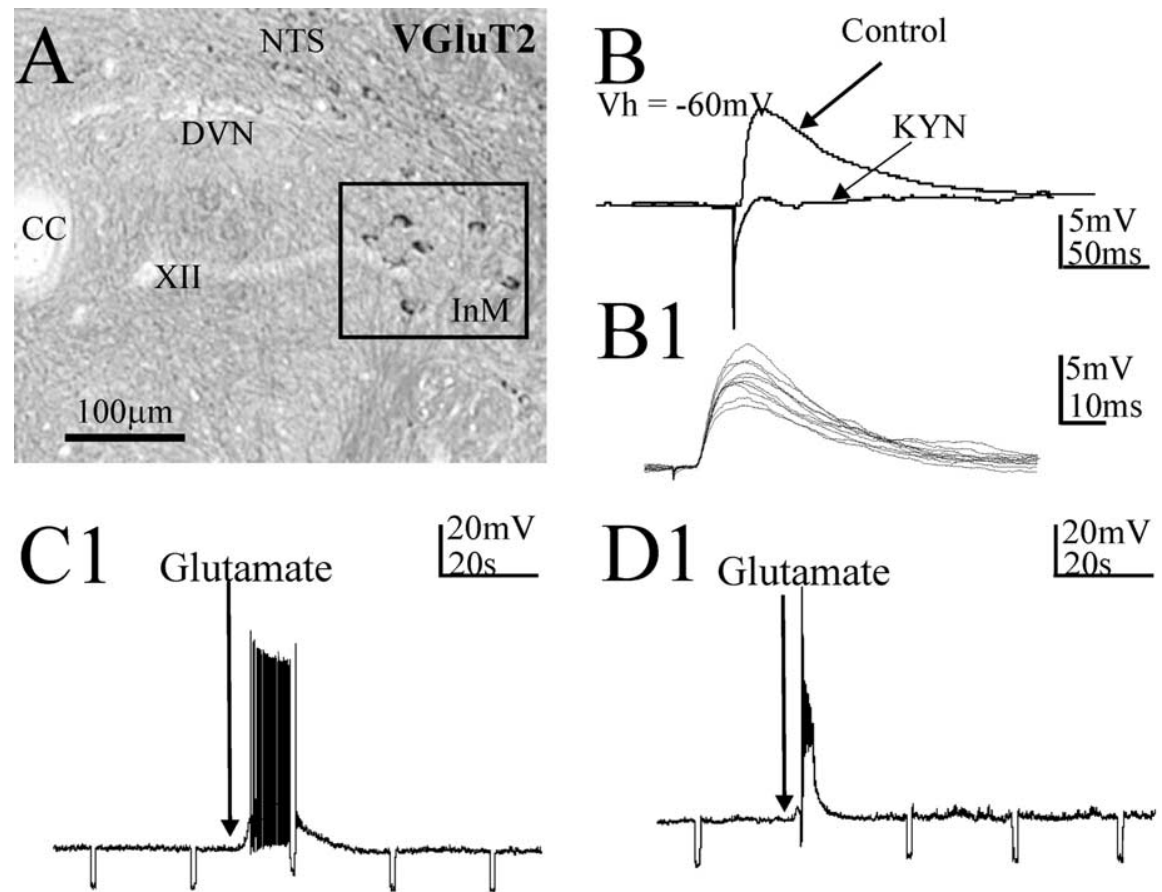

Figure 6. Monosynaptic excitatory projections from the InM to the NTS in the rat revealed electrophysiologically are reflected by (I) 2 expression in InM neurons. $A$, In situ hybridization studies localized neurons within the InM positive for a VGluT2 mRNA probe. The bexts stimulation of the InM. Application of $1 \mathrm{~mm}$ kynurenic acid (KYN) blocked this EPSP. B1, Example of 10 consecutive EPSPs recorded from a I highlighting the minimal synaptic jitter in the excitatory pathway between the InM and NTS. C1, C2, A depolarization elicited in an D1, D2, Local microinjection of glutamate overcomes EAA blockade by bath-applied antagonists. In this example, action potentials within an InM neuron from a holding potential of $-60 \mathrm{mV}$ were observed in response to local microinjection of $40 \mathrm{~mm}$ glutamate in the InM (D1). This response was not blocked by bath application of NBQX (D2). CC, Central canal.

VGluT2 reporter mice such as the GAD-GFP mice used in this study.

In summary, the InM is a little investigated nucleus in the brainstem. This study provides the first examination of its neurochemical diversity alongside initial identification that InM neurons send excitatory and inhibitory projections to the NTS. Future studies will further unravel the functions of this previously unregarded nucleus.

\section{References}

Bakker DA, Richmond FJ, Abrahams VC (1984) Central projections from cat suboccipital muscles: a study using transganglionic transport of horseradish peroxidase. J Comp Neurol 228:409-421.

Bolton PS, Ray CA (2000) Neck afferent involvement in cardiovascular control during movement. Brain Res Bull 53:45-49.

Bolton PS, Kerman IA, Woodring SF, Yates BJ (1998) Influences of neck afferents on sympathetic and respiratory nerve activity. Brain Res Bull 47:413-419.

Bonthius DJ, McKim R, Koele L, Harb H, Karacay B, Mahoney J, Pantazis NJ (2004) Use of frozen sections to determine neuronal number in the mu- 
rine hippocampus and neocortex using the optical disector and optical fractionator. Brain Res Brain Res Protoc 14:45-57.

Brink EE, Suzuki I, Timerick SJ, Wilson VJ (1985) Tonic neck reflex of the decerebrate cat: a role for propriospinal neurons. J Neurophysiol 54:978-987.

Doyle MW, Andresen MC (2001) Reliability of monosynaptic sensory transmission in brain stem neurons in vitro. J Neurophysiol 85:2213-2223.

Edney DP, Porter JD (1986) Neck muscle afferent projections to the brainstem of the monkey: implications for the neural control of gaze. J Comp Neurol 250:389-398.

Esclapez M, Tillakaratne NJ, Tobin AJ, Houser CR (1993) Comparative localization of mRNAs encoding two forms of glutamic acid decarboxylase with nonradioactive in situ hybridization methods. J Comp Neurol 331:339-362.

Esteves FO, McWilliam PN, Batten TF (2000) Nitric oxide producing neurones in the rat medulla oblongata that project to nucleus tractus solitarii. J Chem Neuroanat 20:185-197.

Fiala JC (2005) Reconstruct: a free editor for serial section microscopy. J Microsc 218:52-61.

Fong AY, Stornetta RL, Foley CM, Potts JT (2005) Immunohistochemical localization of GAD67-expressing neurons and processes in the rat brainstem: subregional distribution in the nucleus tractus solitarius. J Comp Neurol 493:274-290.

Fremeau Jr RT, Troyer MD, Pahner I, Nygaard GO, Tran CH, Reimer RJ, Bellocchio EE, Fortin D, Storm-Mathisen J, Edwards RH (2001) The expression of vesicular glutamate transporters defines two classes of excitatory synapse. Neuron 31:247-260.

Fremeau Jr RT, Voglmaier S, Seal RP, Edwards RH (2004) VGLUTs define subsets of excitatory neurons and suggest novel roles for glutamate. Trends Neurosci 27:98-103.

Gritti I, Henny P, Galloni F, Mainville L, Mariotti M, Jones BE (2006) Stereological estimates of the basal forebrain cell population in the rat, including neurons containing choline acetyltransferase, glutamic acid decarboxylase or phosphate-activated glutaminase and colocalizing vesicular glutamate transporters. Neuroscience 143:1051-1064.

Haenggeli C, Kato AC (2002) Differential vulnerability of cranial motoneurons in mouse models with motor neuron degeneration. Neurosci Lett 335:39-43.

Heino R, Westman J (1991) Quantitative analysis of the feline dorsal column nuclei and their GABAergic and non-GABAergic neurons. Anat Embryol (Berl) 184:181-193.

Hongo T, Kitama T, Yoshida K (1988) Integration of vestibular and neck afferent signals in the central cervical nucleus. Prog Brain Res 76:155-162.

Imamura J, Saunders MC, Keller JT (1986) Projections of cervical nerves to the rat medulla. Neurosci Lett 70:46-51.

Knutson GA (2001) Significant changes in systolic blood pressure post vectored upper cervical adjustment vs resting control groups: a possible effect of the cervicosympathetic and/or pressor reflex. J Manipulative Physiol Ther 24:101-109.

Kulkarni V, Chandy MJ, Babu KS (2001) Quantitative study of muscle spindles in suboccipital muscles of human foetuses. Neurol India 49:355-359.

Kuwagata Y, Sugimoto H, Yoshioka T, Sugimoto T (1991) Hemodynamic response with passive neck flexion in brain death. Neurosurgery 29:239-241

Li JL, Wu SX, Tomioka R, Okamoto K, Nakamura K, Kaneko T, Mizuno N (2005) Efferent and afferent connections of GABAergic neurons in the supratrigeminal and the intertrigeminal regions. An immunohistochemical tract-tracing study in the GAD67-GFP knock-in mouse. Neurosci Res 51:81-91.

Lopez-Bendito G, Sturgess K, Erdelyi F, Szabo G, Molnar Z, Paulsen O (2004) Preferential origin and layer destination of GAD65-GFP cortical interneurons. Cereb Cortex 14:1122-1133.

Mackie M, Hughes DI, Maxwell DJ, Tillakaratne NJ, Todd AJ (2003) Distribution and colocalisation of glutamate decarboxylase isoforms in the rat spinal cord. Neuroscience 119:461-472.

Marowsky A, Yanagawa Y, Obata K, Vogt KE (2005) A specialized subclass of interneurons mediates dopaminergic facilitation of amygdala function. Neuron 48:1025-1037.

McKnight ME, DeBoer KF (1988) Preliminary study of blood pressure changes in normotensive subjects undergoing chiropractic care. J Manipulative Physiol Ther 11:261-266.

Morita Y, Zhang JH, Hironaka T, Tateno E, Noguchi K, Sato M, Kiyama H, Tohyama M (1990) Postnatal development of preproenkephalin mRNA containing neurons in the rat lower brainstem. J Comp Neurol 292:193-213.

Neff RA, Mihalevich M, Mendelowitz D (1998) Stimulation of NTS activates NMDA and non-NMDA receptors in rat cardiac vagal neurons in the nucleus ambiguus. Brain Res 792:277-282.

Ono M, Yanagawa Y, Koyano K (2005) GABAergic neurons in inferior colliculus of the GAD67-GFP knock-in mouse: electrophysiological and morphological properties. Neurosci Res 51:475-492.

Paxinos G, Carrive P, Wang H, Wang PY (1999) Chemoarchitectonic atlas of the rat brainstem. San Diego: Academic.

Pfaller K, Arvidsson J (1988) Central distribution of trigeminal and upper cervical primary afferents in the rat studied by anterograde transport of horseradish peroxidase conjugated to wheat germ agglutinin. J Comp Neurol 268:91-108.

Popova LB, Ragnarson B, Orlovsky GN, Grant G (1995) Responses of neurons in the central cervical nucleus of the rat to proprioceptive and vestibular inputs. Arch Ital Biol 133:31-45.

Potts JT (2002) Neural circuits controlling cardiorespiratory responses: baroreceptor and somatic afferents in the nucleus tractus solitarius. Clin Exp Pharmacol Physiol 29:103-111.

Potts JT, Spyer KM, Paton JFR (2000) Somatosympathetic reflex in a working heart-brainstem preparation of the rat. Brain Res Bull 53:59-67.

Potts JT, Paton JF, Mitchell JH, Garry MG, Kline G, Anguelov PT, Lee SM (2003) Contraction-sensitive skeletal muscle afferents inhibit arterial baroreceptor signalling in the nucleus of the solitary tract: role of intrinsic GABA interneurons. Neuroscience 119:201-214.

Prihoda M, Hiller MS, Mayr R (1991) Central projections of cervical primary afferent fibers in the guinea pig: an HRP and WGA/HRP tracer study. J Comp Neurol 308:418-431.

Ramón y Cajal S (1995) Histology of the nervous system of man and vertebrates. Reprint (Swanson N, Swanson LW, translators). New York: Oxford UP.

Richmond FJ, Abrahams VC (1975) Morphology and distribution of muscle spindles in dorsal muscles of the cat neck. J Neurophysiol 38:1322-1339.

Sabatini BL, Regehr WG (1996) Timing of neurotransmission at fast synapses in the mammalian brain. Nature 384:170-172.

Shortt TL, Ray CA (1997) Sympathetic and vascular responses to headdown neck flexion in humans. Am J Physiol 272:H1780-H1784.

Stechison MT, Saintcyr JA (1986) Organization of spinal inputs to the perihypoglossal complex in the cat. J Comp Neurol 246:555-567.

Stornetta RL, Guyenet PG (1999) Distribution of glutamic acid decarboxylase mRNA-containing neurons in rat medulla projecting to thoracic spinal cord in relation to monoaminergic brainstem neurons. J Comp Neurol 407:367-380.

Stornetta RL, Sevigny CP, Guyenet PG (2002) Vesicular glutamate transporter DNPI/VGLUT2 $\mathrm{mRNA}$ is present in $\mathrm{C} 1$ and several other groups of brainstem catecholaminergic neurons. J Comp Neurol 444:191-206.

Takamori S, Rhee JS, Rosenmund C, Jahn R (2000) Identification of a vesicular glutamate transporter that defines a glutamatergic phenotype in neurons. Nature 407:189-194.

Tamamaki N, Yanagawa Y, Tomioka R, Miyazaki JI, Obata K, Kaneko T (2003) Green fluorescent protein expression and colocalization with calretinin, parvalbumin, and somatostatin in the GAD67-GFP knock-in mouse. J Comp Neurol 467:60-79.

Tanaka I, Ezure K, Kondo M (2003) Distribution of glycine transporter 2 mRNA-containing neurons in relation to glutamic acid decarboxylase mRNA-containing neurons in rat medulla. Neurosci Res 47:139-151.

Wilson LB (2000) Spinal modulation of the muscle pressor reflex by nitric oxide and acetylcholine. Brain Res Bull 53:51-58.

Wilson VJ, Ezure K, Timerick SJ (1984) Tonic neck reflex of the decerebrate cat: response of spinal interneurons to natural stimulation of neck and vestibular receptors. J Neurophysiol 51:567-577.

Wuenschell CW, Fisher RS, Kaufman DL, Tobin AJ (1986) In situ hybridization to localize mRNA encoding the neurotransmitter synthetic enzyme glutamate decarboxylase in mouse cerebellum. Proc Natl Acad Sci USA 83:6193-6197.

Yates BJ, Miller AD (1994) Properties of sympathetic reflexes elicited by natural vestibular stimulation: implications for cardiovascular control. J Neurophysiol 71:2087-2092.

Zhang C, Szabo G, Erdelyi F, Rose JD, Sun QQ (2006) Novel interneuronal network in the mouse posterior piriform cortex. J Comp Neurol 499: $1000-1015$. 